Chronisch obstruktive Lungenerkrankung

\section{Beeinflusst ein Gen das Erkrankungsrisiko?}

Hunninghake GM et al. MMP12, lung function, and COPD in high-risk populations.

N Engl J Med. 2009;361:2599-2608

\section{Hintergrund und Fragestellung}

Dieser Arbeit lag die Hypothese zugrunde, dass Polymorphismen (singlenucleotide polymorphisms, SNP) im Gen für die Matrixmetalloproteinase 12 (MMP12) die Lungenfunktion beeinflussen.

Über 20000 Lungenfunktionsmessungen an 8300 Personen, die aus sieben Kohorten rekrutiert wurden (Genetics of Asthma Costa Rica Study, Childhood Asthma Management Program, Children Allergy Milieu Stockholm Epidemiological Survey, Boston Ealy-Osnet COPD Study, National Emphysema Treatment Trial, Lovlace Smokers Cohort, Normative Aging Study) wurden im Zusammenhang mit den SNP im MMP12-Gen gebracht.

\section{Ergebnisse}

Das Minorallel (G) in der Promotorhatte einen protektiven Einfluss auf die

\section{Methodik} region des MMP12-Gens (rs2276109)
Einsekundenkapazität $\left(\mathrm{FEV}_{1}\right)$ und reduzierte das COPD-Risiko bei Rauchern um bis zu 35\% ( $\mathrm{p}=0,005)$. Umgekehrt führte das Fehlen dieses Allels zu einem Risikoanstieg von 54\%. Die Überlebenskurven sind in Abbildung 1 dargestellt.

\section{Kommentar}

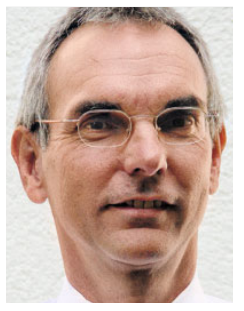

Prof. Dr. med. Adrian Gillissen, Leipzig

Die Expression von MMP12 ist mit einem beschleunigten Elastinabbau in den kleinen Atemwegen und in der Folge mit der Entstehung eines Lungenemphysems assoziiert. Alveolarmakrophagen von Rauchern haben eine neunfach höhere MMP12-Expression als die von Nichtrauchern. Asthma

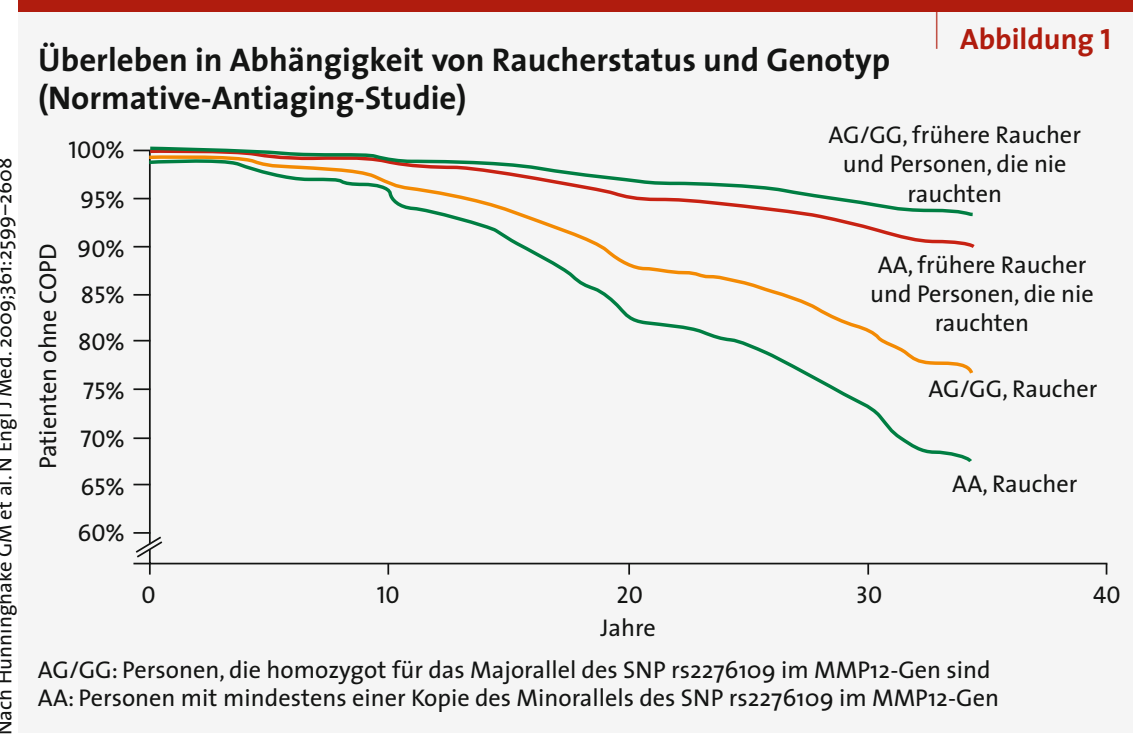

oder die Exposition von inhalativen Noxen während der Kindheit können über MMP12 eine spätere COPD-Entwicklung fördern.

Der Charme dieser großen Untersuchung ist, dass verschiedene Studienkohorten einschließlich Kinder und Erwachsene, teilweise sogar mehrfach über einen langen Zeitraum, eingeschlossen wurden und eine recht gute Übereinstimmung der Ergebnisse in Bezug auf die protektive Funktion der MMP12-SNP ergeben haben.

Es gibt viele Genpolymorphismusstudien für die COPD, so z.B. zu den Genen für den Toll-like-Rezeptor (TLR) [5], den Beta-2-Rezeptor [8] und den Kortikosteroidrezeptor [7] sowie für Gene, die für diverse Entzündungsmediatoren, Antiproteasen, Proteasen etc. kodieren. Viele dieser Studien haben aber methodische Schwächen, da die Patientenzahlen zu klein, das Patientenkollektiv zu heterogen oder die klinischen Kontroll- oder Erfolgsparameter zur Beschreibung des Phänotyps nicht sauber definiert waren.

Ist nun endlich das so lange postulierte „COPD-Risikogen“ gefunden? Wohl kaum, da es sich bei der COPD um eine multifaktorielle Erkrankung handelt. Ebenso ist es keineswegs möglich, das individuelle COPD- oder Emphysemrisiko über die Bestimmung des MMP12-Genpolymorphismus-Status abzuschätzen. Da aber auch das Ausmaß der Lungenfunktionseinschränkung asthmakranker Kinder eine Abhängigkeit vom MMP12-Genstatus aufwiesen, bietet diese Studie einen bemerkenswerten Einblick in den Einfluss einer singulären Genmodifikation und deren pulmonale Auswirkung, die bisher nur beim Alpha-1-Antitrypsin bekannt war [6].

Angesichts dieser doch recht eindeutigen Datenlage würde sich die Inhibition des MMP12-Proteins z.B. mithilfe eines Antikörpers zur antiinflammatorischen COPDTherapie eignen. Darauf weisen Untersuchungen an Mäusen hin [3].

\footnotetext{
Literatur

1. DeMeo DLetal.Semin Respir Crit Care Med.2003;24 151-159

2. Joos L et al. Swiss Med Wkly. 2002;132:27-37

3. Le Quément C et al. Brit J Pharmacol. 2008;154: 1206-1215

4. Litonjua AA et al. Chest 2004;126:66-74

5. Pabst $S$ et al. Lung 2009;187:173-178

6. Sampsonas F et al. Curr Med Chem. 2006;13:28572873

7. Schwabe K et al. Eur J Med Res. 2009;14:210-215

8. Vacca G et al. Ther Adv Respir Dis. 2009;3:3-10
} 